\title{
Facile Carbonyl Sulfide (COS) Fixation into Novel COS-Storage Materials Towards Preparation of CdS Photocatalyst for $\mathrm{CO}_{2}$ Reduction and Promotion of Plant Growth
}

\author{
Bin $\mathrm{Li}^{1,2}$, Tingyu Yang ${ }^{2,3}$, Xiaoqing Yue ${ }^{2,4}$, Zhaojun $\mathrm{Wu}^{2}$, Jianbin Zhang ${ }^{1,2^{*}}$ \\ ${ }^{1}$ Hebei Provincial Key Lab of Green Chemical Technology and High Efficient Energy Saving, School of Chemical Engineering and \\ Technology, Hebei University of Technology, Tianjin, China \\ ${ }^{2}$ Inner Mongolia Engineering Research Center for $\mathrm{CO}_{2}$ Capture and Utilization, College of Chemical Engineering, Inner Mongolia \\ University of Technology, Hohhot, China \\ ${ }^{3}$ College of Life and Environmental Science, Minzu University of China, Beijing, China \\ ${ }^{4}$ Materials Science and Engineering, Harbin Institute of Technology, Heilongjiang, China \\ E-mail: tadzhang@pku.edu.cn
}

Received: 11 November 2021; Revised: 11 January 2022; Accepted: 17 January 2022

Abstract: An effective approach to the COS capture and fixation using the alcohol-amine binary systems contained Ethylene Glycol-based polyols (EGs) and Ethylenediamine-based polyamines (EDAs) under ambient conditions is developed. Fourier-Transform Infrared spectroscopy (FTIR), X-ray Photoelectron Spectroscopy (XPS) and X-Ray powder Diffraction (XRD) analyses reveal that COS is converted into thio-alkylcarbonate salts with the special chemical structures of $\left[{ }^{+} \mathrm{H}_{3} \mathrm{NR}_{1} \mathrm{NH}_{3}{ }^{+-} \mathrm{OC}(=\mathrm{S}) \mathrm{OR}_{2}\left(\mathrm{R}_{3}\right) \mathrm{O}(\mathrm{S}=) \mathrm{CO}^{-}\right]_{\mathrm{n}}$, which are named as a COS-Storage Material (COSSM). Notably, the COSSM is successfully applied to the synthesis of CdS Nano-Particles (NPs) for the photocatalytic conversion of $\mathrm{CO}_{2}$ to $\mathrm{CO}$ and $\mathrm{CH}_{4}$, and used as a nitro-sulfur compound fertilizer to promote plant growth. Our work has provided a readily available strategy for the green storage and sustainable utilization of COS.

Keywords: carbonyl sulfide, COS-storage materials, CdS nano-particles, nitro-sulfur compound fertilizer, photocatalysis

\section{Graphical abstract}

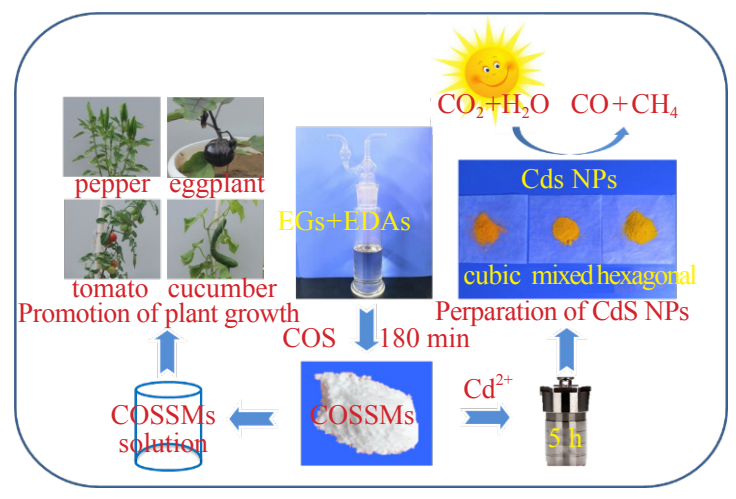

Copyright (C2022 Jianbin Zhang, et al.

DOI: https://doi.org/10.37256/sce.3120221240

This is an open-access article distributed under a CC BY license

(Creative Commons Attribution 4.0 International License)

https://creativecommons.org/licenses/by/4.0/ 


\title{
Abbreviation
}

\author{
COS: carbonyl sulfide \\ EGs: ethylene glycol-based polyols \\ EDAs: ethylenediamine-based polyamines \\ COSSMs: COS-storage materials \\ EG: ethylene glycol \\ DEG: diethylene glycol \\ TEG: triethylene glycol \\ TeEG: tetraethylene glycol \\ PEG 300: polyethylene glycol 300 \\ PEG 400: polyethylene glycol 400 \\ DPG: dipropylene glycol \\ PPD: 1,2-propanediol \\ BDO: 1,3-butanediol \\ EDA: ethylenediamine \\ PDA: 1,3-propanediamine \\ HDA: 1,6-hexanediamine \\ $\mathrm{Cd}\left(\mathrm{NO}_{3}\right)_{2}$ : cadmium nitrate \\ NPs: nano-particles \\ $\mathrm{KBr}$ : potassium bromide \\ FTIR: Fourier transform infrared spectroscopy \\ XPS: X-ray photoelectron spectroscopy \\ XRD: X-ray diffraction \\ SEM: scanning electron microscope \\ $\mathrm{CH}_{2} \mathrm{Cl}_{2}$ : dichloromethane \\ DMSO: dimethyl sulfoxide \\ TEOA: triethanolamine \\ CO: carbon monoxide \\ $\mathrm{CH}_{4}$ : methane
}

\section{Introduction}

COS, an organic sulfur compound, is the most abundant trace gas in the atmosphere with an average tropospheric lifetime of 2-6 years. ${ }^{1,2}$ It plays a vital role in global sulfur circulation. ${ }^{3}$ At present, COS is widely found in natural gas, petroleum gas, water gas, and industrial waste gas due to human activities. ${ }^{4,5}$ In industrial productions, COS can be combusted into acidic $\mathrm{SO}_{2}$ that greatly reduces the lifetimes of catalysts and apparatuses. ${ }^{6,7}$ Therefore, the removal of $\mathrm{COS}$ from various gases is an important operation for industrial production and environmental protection. ${ }^{8,9}$

Many techniques have been developed for COS removals, such as hydrogenation, hydrolysis, organic amine solvent absorption, and oxidation. ${ }^{10,11}$ Among them, organic amine scrubbing displays remarkable advantages of rapid removal rates and low costs. However, the highly volatile amines can cause secondary pollution of Volatile Organic Compounds (VOCs). Inspired by the amines fixing ability of Ethylene Glycol (EG) via forming hydrogen bonding, ${ }^{12}$ we attempted to reduce the volatility of polyamines using polyols for better COS capture performances. During the study of COS capture with EGs and EDAs, we unexpectedly found that the binary systems of EG and EDA could effectively and rapidly capture and store $\operatorname{COS}$ in the form of white solid powder under ambient conditions. Further investigation revealed that COS could react with EGs and EDAs to produce COSSMs. Therefore, expanding the scope of the alcoholamine system for COS fixation can significantly promote the study of COS removal.

Some semiconductors, such as CdS NPs, have demonstrated excellent photocatalytic activities and selectivity for $\mathrm{CO}_{2}$ reduction under visible light irradiation. ${ }^{13,14} \mathrm{CdS}$ NPs are often synthesized in the presence of additives at high 
temperatures with costly pure substances. ${ }^{15,16}$ Therefore, in the present work, we attempt to develop a simple and lowcost synthesis method of CdS NPs using COSSMs as both sulfur source and facilitative surfactants for the first time.

Sulfur (S) is a key element for plant growth, especially for the synthesis of essential amino acids, such as methionine, cystine, and cysteine. ${ }^{17}$ It is mainly in the forms of sulfur and sulfate in soil, ${ }^{18,19}$ and the lack of sulfur may result in serious reductions in the yield and quality of crops. ${ }^{20,21}$ The studies, developments, and applications of sulfur fertilizers for sustainable agricultural development are of great significance and indispensability. Herein, the application potentials of the sulfur-containing COSSMs as a sulfur fertilizer were also explored for promoting plant growth. On this basis, COSSMs were used as an indirect $\mathrm{S}$ source to promote the growth of cucurbitaceous and solanaceous crops. Among them, cucumber was a cucurbitaceous plant; pepper, eggplant, and tomato were solanaceous plants.

In the present work, various EGs + EDAs systems were prepared and examined for COS capture under ambient conditions. The COSSMs formed with these systems were characterized by FTIR, XPS, and XRD as thio-alkylcarbonate salts. CdS NPs photocatalysts were successfully prepared with these thio-alkylcarbonate salts by hydrothermal reaction, and their photocatalytic activities were evaluated for the conversion of $\mathrm{CO}_{2}$ to $\mathrm{CO}$ and $\mathrm{CH}_{4}$. The COSSMs were also found an excellent nitro-sulfur fertilizer for promoting four plants' growth because of their good water solubility.

\section{Experimental}

\subsection{Synthesis of COSSMs}

EGs including EG, Di-Ethylene Glycol (DEG), Tri-Ethylene Glycol (TEG), Tetra-Ethylene Glycol (TeEG), PolyEthylene Glycol 300 (PEG300), Poly-Ethylene Glycol 400 (PEG400), Dipropylene Glycol (DPG), 1,2-Propanediol (PPD) and 1,3-Butanediol (BDO), and EDAs including ethylenediamine (EDA), 1,3-Propanediamine (PDA) and 1.6-Hexanediamine (HDA) were respectively subjected to dehydration and decontamination through $4 \AA$ molecular sieves and degassed by ultrasonication before use. Our previous work suggests that the interactions among the molecules in solution are strongest at the 1:1 molar ratio of EDAs to EGs. ${ }^{22,23}$ Therefore, $40 \mathrm{~g}$ of EGs + EDAs solution with the molar ratio of 1:1 and $1.5 \mathrm{~g}$ of water were firstly added into a gas absorption bottle. COS gas was introduced into the solution at the flow rate of $10 \mathrm{~mL} / \mathrm{min}$ for $\sim 3 \mathrm{~h}$ when floccus appeared. The floccus was collected, washed with absolute ethanol three times or more, and vacuum dried at $35^{\circ} \mathrm{C}$ for $2 \mathrm{~h}$ to afford COSSMs as a white powder. Figure 1 presents the preparation process of COSSMs.

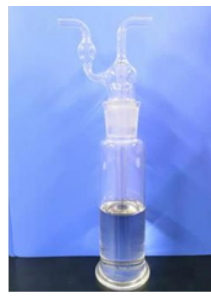

EGs + EDAs

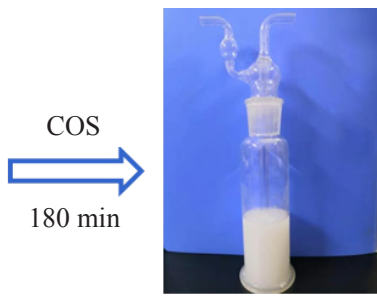

$\mathrm{EGs}+\mathrm{EDAs}$

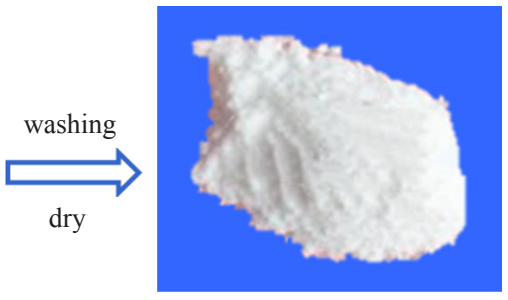

COSSMs

Figure 1. Preparation process of COSSMs

\subsection{Preparation of CdS NPS}

CdS NPs with cubic phase and both cubic and hexagonal phases were prepared by the hydrothermal reactions of $50 \mathrm{~mL}$ of $0.05 \mathrm{~mol} / \mathrm{L} \mathrm{Cd}\left(\mathrm{NO}_{3}\right)_{2}$ solutions and $0.1 \mathrm{~g}$ and $1 \mathrm{~g}$ EG-based COSSMs, respectively, at $180{ }^{\circ} \mathrm{C}$ for $5 \mathrm{~h}$. The $\mathrm{CdS}$ NPs with hexagonal phase were prepared by the hydrothermal reaction of $50 \mathrm{~mL}$ of $0.05 \mathrm{~mol} / \mathrm{L} \mathrm{Cd}\left(\mathrm{NO}_{3}\right)_{2}$ solution with $1 \mathrm{~g} \mathrm{EG-COSSM}$ in a $100 \mathrm{~mL}$ Teflon-line stainless steel reactor at $60^{\circ} \mathrm{C}$ for $5 \mathrm{~h}$. The as-prepared CdS precipitates were respectively centrifuged, washed with water and ethanol more than 3 times, and vacuum dried at $60^{\circ} \mathrm{C}$ for $6 \mathrm{~h}$.

The application of the prepared CdS NPs as the photocatalyst was evaluated for the photocatalytic reduction of 
$\mathrm{CO}_{2}$ to $\mathrm{CH}_{4}$ and $\mathrm{CO}$ using the NPs prepared with the EG-based COSSM as an example. The reaction was conducted in an apparatus consisting of a $300 \mathrm{~W}$ Xenon lamp with the light power of $278 \mathrm{~mW}$ at an optical power density of 370 $\mathrm{mW} / \mathrm{cm}^{2}$ in the range of 14-21 A as the light source (Figure S1). The gas composition was quantitatively analyzed using a GC-7920 instrument by the external calibration method.

\subsection{Application of COSSMs as fertilizer}

The application of the as-prepared COSSMs as fertilizer was explored for the growth of four plants. The experimental groups and control groups were grown in the flowerpots with the sizes of $36 \mathrm{~cm} \times 24 \mathrm{~cm}$ under the same conditions. The experimental group and control group each contained 3 pots of different plants. The solutions of EGCOSSM, DEG-COSSM, TEG-COSSM, TeEG-COSSM, PEG300-COSSM, PEG 400-COSSM, PPD-COSSM, DPGCOSSM, and $\mathrm{NH}_{4} \mathrm{HCO}_{3}$ were prepared by dissolving $2.4 \mathrm{~g}$ of the substance in $600 \mathrm{~mL}$ water. The experimental groups were irrigated with $50 \mathrm{~mL}$ of the solution of COSSs and the two control groups were irrigated with the same amounts of $\mathrm{NH}_{4} \mathrm{HCO}_{3}$ and water, respectively. The plants were photographed and plant heights were measured every 7 days for 60 days, and the total number of flowers was recorded.

\section{Results and discussion}

\subsection{Preparation of COSSMS}

Table 1. Conductance values, melting point, Increment of different alcohols, amines, mixtures and COSSMs

\begin{tabular}{|c|c|c|c|c|c|}
\hline Entry & $\begin{array}{l}\text { Alcohol (Conductivity } \\
\left.\left[\mu \mathrm{s} \cdot \mathrm{cm}^{-1}\right] / \text { Quality }[\mathrm{g}]\right)\end{array}$ & $\begin{array}{l}\text { Amine (Conductivity } \\
\left.\left[\mu \mathrm{s} \cdot \mathrm{cm}^{-1}\right] / \text { Quality }[\mathrm{g}]\right)\end{array}$ & Increment $(\mathrm{g})^{\mathrm{a}}$ & Melting point $\left[{ }^{\circ} \mathrm{C}\right]$ & $\begin{array}{l}\text { Mixture conductivity/Ventilation } \\
2 \mathrm{~h} / \mathrm{COSSMs} \text { Solution }\left[\mu \mathrm{s}^{-} \mathrm{cm}^{-1}\right]\end{array}$ \\
\hline 1 & EG $(0.34 / 24.8281)$ & $\operatorname{EDA}(1.12 / 24.0694)$ & 11.8875 & $100.5-105.9$ & $338 / 1323 / 525$ \\
\hline 2 & DEG $(0.12 / 31.8367)$ & $\operatorname{EDA}(1.12 / 18.0433)$ & 4.6640 & $86.4-91.1$ & $100.8 / 805 / 632$ \\
\hline 3 & TEG $(0.21 / 30.0306)$ & $\operatorname{EDA}(1.12 / 12.0202)$ & 2.8333 & $104.3-252.6$ & $7.02 / 299 / 593$ \\
\hline 4 & TeEG $(0.21 / 38.8740)$ & $\operatorname{EDA}(1.12 / 12.0442)$ & 6.1427 & $83.1-85.9$ & $71 / 276 / 586$ \\
\hline 5 & PEG300 (3.37/60.0095) & $\operatorname{EDA}(1.12 / 12.0106)$ & 2.8119 & $91.0-219.4$ & $45 / 118.8 / 746$ \\
\hline 6 & PEG400 (6.01/40.0093) & $\operatorname{EDA}(1.12 / 6.0432)$ & 3.7259 & $110.6-230.5$ & $10.9 / 31.2 / 696$ \\
\hline 7 & DPG (0/26.8353) & $\operatorname{EDA}(1.12 / 12.0244)$ & 4.6467 & $99.8-227.9$ & $2.82 / 178.9 / 681$ \\
\hline 8 & PPD $(0.21 / 22.8295)$ & $\operatorname{EDA}(1.12 / 18.0257)$ & 6.5910 & $161.9-167.8$ & $16.41 / 613 / 546$ \\
\hline 9 & $\mathrm{BDO}(0.055 /-)$ & $\operatorname{EDA}(1.12 /-)$ & - & $107.4-288.0$ & $16.52 / 454 / 549$ \\
\hline 10 & $\mathrm{EG}(0.34 /-)$ & $\operatorname{PDA}(2.15 /-)$ & - & $253.4-261.1$ & $16.7 / 1412 / 533$ \\
\hline 11 & $\mathrm{EG}(0.34 /-)$ & $\operatorname{HDA}(0.37 /-)$ & - & $177.8-289.5$ & $4.07 / 394 / 865$ \\
\hline
\end{tabular}

-: unobtained data

a: Inexact value

All the binary systems of EGs and EDAs become thick, and eventually, white solids are formed after COS is introduced (Figure 1). The solution temperature increases first and then decreases to room temperature during the reaction. The conductivities of the solutions of EGs, EDAs, and their mixture systems can be found in our previous work. ${ }^{24}$ The introduction of COS first increases and then decreases the conductivities of the EGs + EDAs binary systems (Table 1). The abrupt change in conductivity can be due to the chemical absorption of COS by EGs + EDAs binary system. The 
changing trends of temperature, viscosity, and conductivity of the EGs + EDAs binary systems during COS absorption are similar to those during their absorptions of $\mathrm{CO}_{2}$ and $\mathrm{CS}_{2}{ }^{22,24}$ However, due to the concerns that the emission of COS into the atmosphere will influence the environment, the changes of temperature, weight, and conductivity with the prolongated absorption time were not further measured.

Slowly bubbling COS causes a series of changes in the properties of the EGs + EDAs binary systems, including viscosity, temperature, and conductivity, which is due to the reaction of EGs, EDAs, and COS and the formation of new compounds. The accumulation of ions in the solution enhances the electrostatic interaction between the anions and cations, which increases the viscosity and reduces the fluidity of the binary system. ${ }^{25}$ The reaction is exothermic, and thus the temperature of the system increases during the reaction. The formation of new compounds gradually increases the viscosity of the system, which slows the diffusion of reactants and thus inhibits the reaction. White precipitates (COSSMs) are formed as the contents of the new compounds are greater than their solubility. Once the COSSMs are precipitated, the viscosity, temperature, and conductivity of the reaction system are all lowered.

As it can be seen from Table 1, as the reaction preceded the movements of anions and cations are accelerated in the solution. The accelerated collision between the ions enhances the ability of electrons to transfer charges in the solution. ${ }^{26}$ The conductivity decreases with the increase of the number of carbon atoms in the linear alcohol or amine. The elongation of the carbon chain results in higher degrees of anion-cation association mainly because of the enhanced via van der Waals' forces between the alkyl carbon chains. ${ }^{27}$ In addition, with the continuous elongation of the carbon chain, the mobility of ions is decreased, which reduces the pairing possibility of the anions and cations, resulting in the decrease of conductivity. ${ }^{28}$

\subsubsection{Characterizations of COSSMS}

\subsubsection{FTIR and XRD}

FTIR spectra and XRD patterns of various COSSMs are shown in Figure 2.

The as-obtained white products exhibit similar FTIR spectra (Figure 2a). The sharp peak at $3330 \mathrm{~cm}^{-1} \mathrm{can} \mathrm{be}^{-1}$ assigned to the stretching vibration of N-H. ${ }^{29}$ The characteristic peaks at around $1580 \mathrm{~cm}^{-1}$ and $758 \mathrm{~cm}^{-1}$ are attributed to the stretching vibration and the in-plane rocking vibration of $-\mathrm{NH}_{3}{ }^{+}$, respectively. ${ }^{30}$ The peak at $\sim 1432 \mathrm{~cm}^{-1}$ is due to the shear vibration of $-\mathrm{CH}_{2}{ }^{31}$ and the peak at $\sim 1052 \mathrm{~cm}^{-1}$ is ascribed to the stretching vibration of C-O-C. ${ }^{32}$ The peak at $\sim 1162 \mathrm{~cm}^{-1}$ is caused by the stretching vibration of $\mathrm{C}-\mathrm{O} .{ }^{33}$ The characteristic peak at $\sim 1222 \mathrm{~cm}^{-1}$ is the stretching vibration of $\mathrm{C}=\mathrm{S} .{ }^{34}$ These results suggest that there are $\mathrm{C}=\mathrm{S}, \mathrm{C}-\mathrm{O}, \mathrm{C}-\mathrm{O}-\mathrm{C}, \mathrm{N}-\mathrm{H},-\mathrm{CH}_{2}$, and $-\mathrm{NH}_{3}{ }^{+}$in the as-obtained COSSMs.

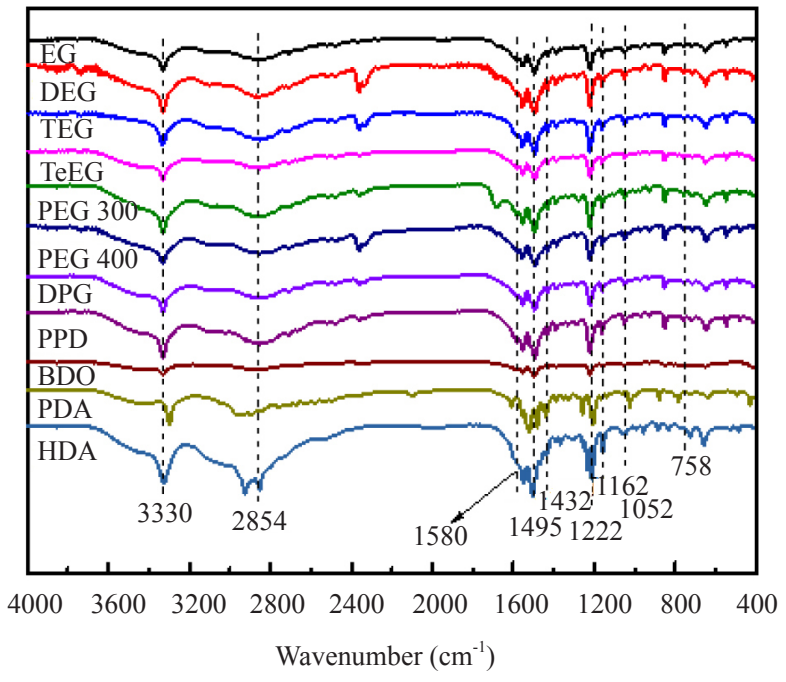

(a)

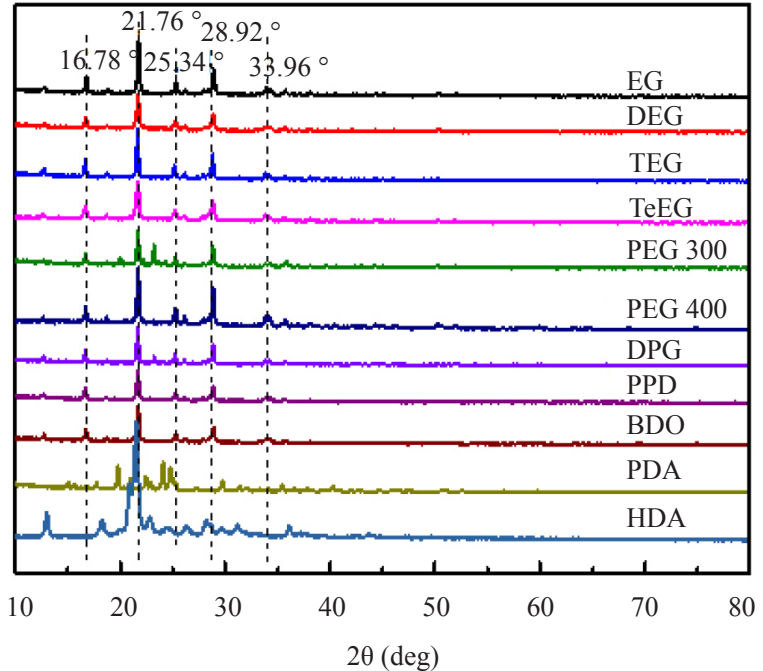

(b)

Figure 2. FTIR spectra (a) and XRD patterns (b) of different COSSMs 

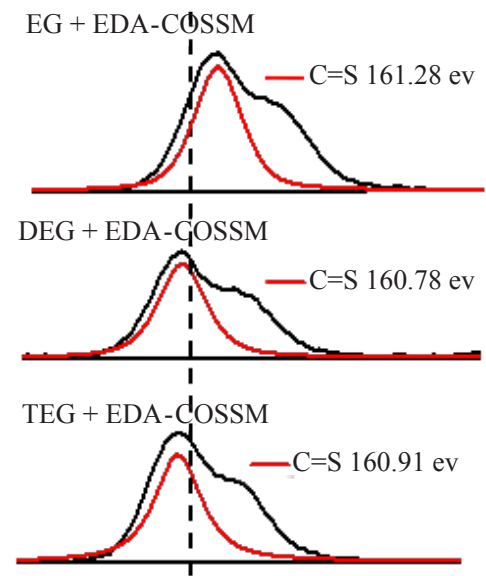

TeEG + EDA-COSSM

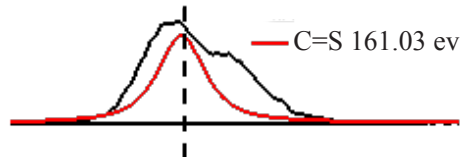

PEG $300+$ EDA-COSSM

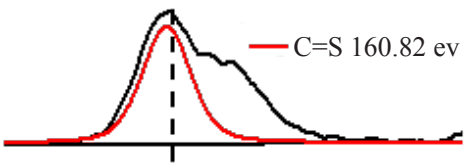

PEG $400+$ EßA-COSSM

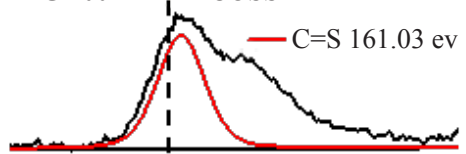

$\mathrm{DPG}+\mathrm{EDA}-\mathrm{COSSM}$

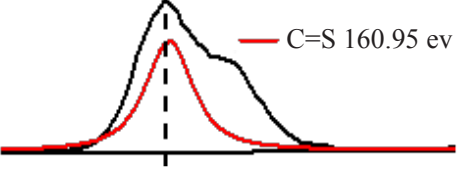

PPD + EDA-COSSM
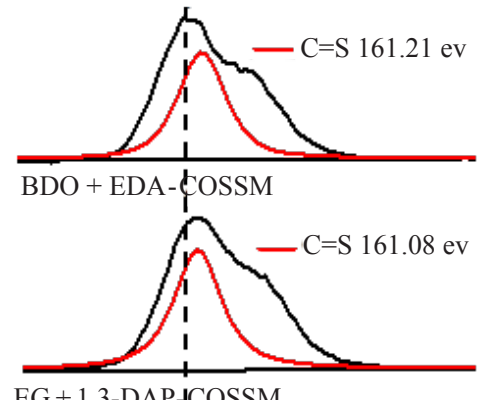

$\mathrm{EG}+1,3-\mathrm{DAP}\lrcorner \mathrm{COSSM}$
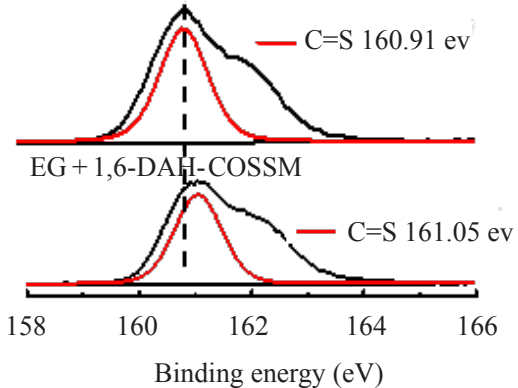

Figure 3. High resolution XPS spectra of S(2p) of COSSMs 
Figure $2 \mathrm{~b}$ shows the XRD patterns of the COSSMs obtained by the reaction of EGs, EDA, and COS. The strong diffraction peaks at $16.78^{\circ}, 21.76^{\circ}, 25.34^{\circ}, 28.92^{\circ}$, and $33.96^{\circ}$ are like the characteristic diffraction peaks of sulfadiazine (JCPDS 49-2414), ${ }^{35}$ indicating the high degree of crystallinity of the COSSMs and the presence of $\mathrm{C}=\mathrm{S}$.

\subsubsection{XPS}

The as-prepared COSSMs exhibit XPS peaks at $162.08 \mathrm{eV}, 285.08 \mathrm{eV}, 400.08 \mathrm{eV}$, and $531.08 \mathrm{eV}$ that can be assigned to $\mathrm{S}(2 \mathrm{p}), \mathrm{C}(1 \mathrm{~s}), \mathrm{N}(1 \mathrm{~s})$, and $\mathrm{O}(1 \mathrm{~s})$, respectively (Figure 3 and Figure $\mathrm{S} 2$ ). The $\mathrm{O}(1 \mathrm{~s})$ narrow scan XPS spectra can be fitted into two peaks at $530.95 \mathrm{eV}$ and $532.98 \mathrm{eV}$, corresponding to the $\mathrm{O}$ in C-O-C and the alcoholic hydroxyl group, respectively ${ }^{36}$ (Figure S2). The $\mathrm{C}(1 \mathrm{~s})$ spectra are deconvoluted into 5 peaks at $284.68 \mathrm{eV}, 285.48 \mathrm{eV}, 286.18 \mathrm{eV}$, $286.38 \mathrm{eV}$, and $288.48 \mathrm{eV}$, that are assigned to the $\mathrm{C}$ in $\mathrm{C}-\mathrm{C}, \mathrm{C}-\mathrm{N}, \mathrm{C}-\mathrm{H}, \mathrm{C}-\mathrm{O}$, and $\mathrm{C}=\mathrm{S}$, respectively ${ }^{37}$ (Figure S2). The N(1s) narrow scan XPS spectra are composed of two peaks at $399.08 \mathrm{eV}$ and $400.73 \mathrm{eV}$ that are attributed to the $\mathrm{N}$ in $-\mathrm{NH}_{3}{ }^{+}$and $\mathrm{C}-\mathrm{N}^{38}$ (Figure S2). The peaks at $161.28 \mathrm{eV}$ on the $\mathrm{S}(2 \mathrm{p})$ spectra confirm the formation of $\mathrm{C}=\mathrm{S}$ in the $\mathrm{COSSMs}^{39}$ (Figure 3). These results suggest that the as-obtained COSSMs are mainly constructed with $\mathrm{C}=\mathrm{S}, \mathrm{C}-\mathrm{O}, \mathrm{C}-\mathrm{O}-\mathrm{C}$, $\mathrm{C}-\mathrm{N}$, and $-\mathrm{NH}_{3}^{+}$.

Based on the FTIR, XRD, and XPS results, the structure of COSSMs is determined to be $\left[{ }^{+} \mathrm{H}_{3} \mathrm{NR}_{1} \mathrm{NH}_{3}{ }^{+-} \mathrm{OC}(=\mathrm{S})\right.$ $\left.\mathrm{OR}_{2}\left(\mathrm{R}_{3}\right) \mathrm{O}(\mathrm{S}=) \mathrm{CO}^{-}\right]_{\mathrm{n}}$.

\subsubsection{Formation mechanism of COSSMS}

Based on the FTIR, XRD, and XPS characterization results, the plausible formation mechanism of COSSMs in the EGs + EDAs binary systems is proposed, as shown in Figure 4. First, the $\mathrm{H}$ atom in the hydroxyl group of alcohol forms a hydrogen bond with the $\mathrm{N}$ atom in the $-\mathrm{NH}_{2}$ of amine, ${ }^{40}$ which deprotonates the alcohol and protonates the amine, especially for the highly alkaline amines. ${ }^{41}$ This also explains the increased conductivities as EGs and EDAs mixed. As EGs and EDAs mixed at the molar ratio of 1:1, $-\mathrm{NH}_{2}$ cannot be completely protonated. However, COS tends to attract electrons, and thus attack the electron-rich region. Finally, the $\mathrm{C}=\mathrm{O}$ bond of $\mathrm{COS}$ is then broken to form mono-thioalkylammonium carbonate. According to the characterizations of COSSM, we present the formation mechanism is $\left[\mathrm{H}_{2} \mathrm{~N}-\mathrm{R}-\right.$ $\mathrm{NH}_{2}+\mathrm{HO}-\mathrm{R}^{\prime}-\mathrm{OH}+\mathrm{COS}=\left[{ }^{+} \mathrm{H}_{3} \mathrm{~N}-\mathrm{R}-\mathrm{NH}_{3}{ }^{+} \cdot \mathrm{O}-\mathrm{C}(=\mathrm{S}) \mathrm{O}-\mathrm{R}^{\prime}-\mathrm{O}-\mathrm{C}(=\mathrm{O})-\mathrm{O}^{-}\right]_{\mathrm{n}}$. However, some processes need future researches.

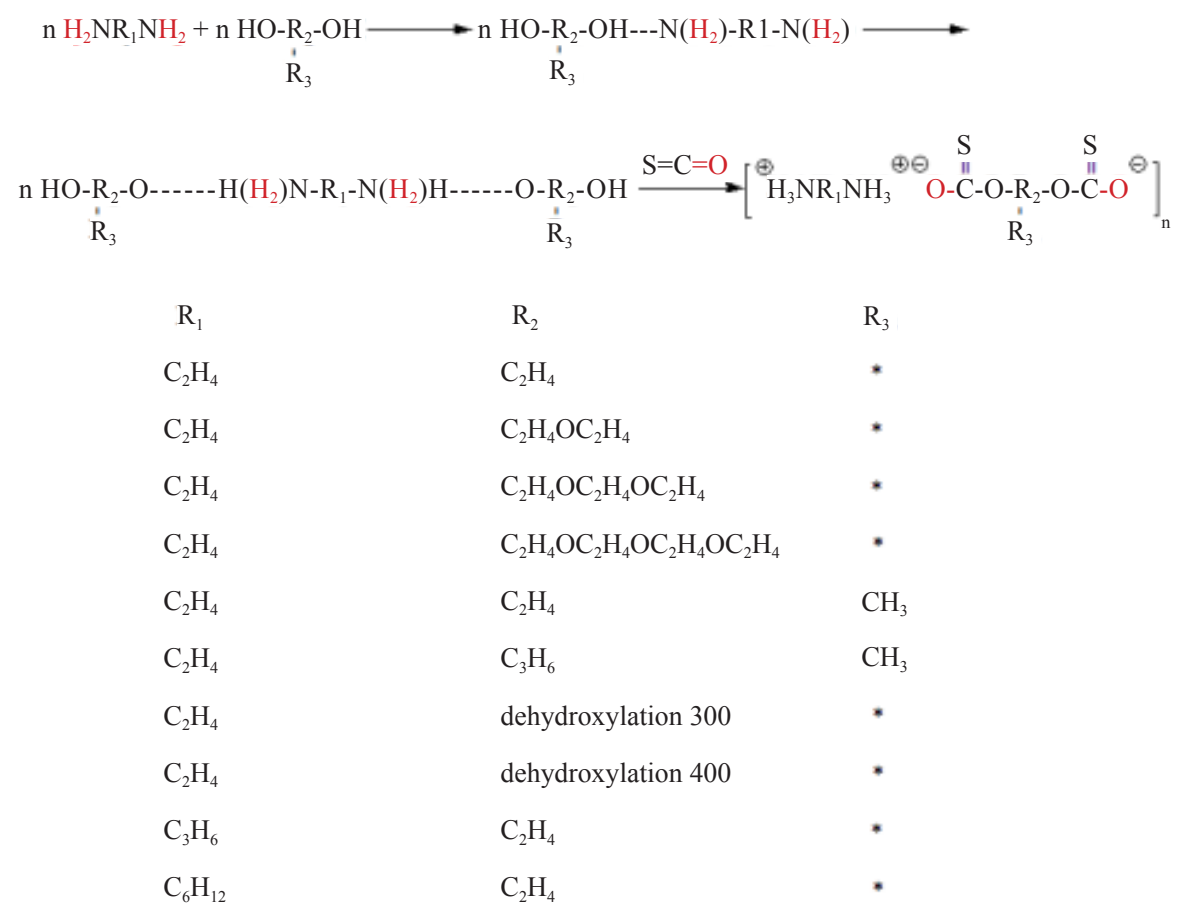

Figure 4. Formation mechanism of COSSM under EGs + EDAs system 


\subsubsection{Property characterization of COSSMs}

\subsubsection{Melting point}

The COSSMs prepared in different EGs + EDAs binary systems exhibit different melting points in a wide range from $83.1{ }^{\circ} \mathrm{C}$ to $289.5^{\circ} \mathrm{C}$ (Table 1). Yet, the melting point increases with the increases of the polymerization degrees of EGs and EDAs. It can be explained that the melting point of an ionic liquid is decided by the size and symmetry of its anion and cation. In general, the smaller the size and the better the symmetry of the cation, the higher the melting point. ${ }^{42}$ For the same cation, the melting point mainly depends on the size of the anion. The anions with larger sizes usually form ionic liquids of higher melting points.

\subsubsection{Solubility}

As shown in Table 2, the preliminary tests reveal that the COSSMs are highly water soluble in water and insoluble in organic solvents, such as anhydrous ethanol, di-chloromethane, tri-chloromethane, and so on. Further investigation reveals that the polar COSSMs are soluble in water and insoluble in low polarity solvents, including diethyl ether and hexane. Moderate solubility is observed in moderately polar and high polar solvents ethyl acetate and dimethyl sulfoxide. In addition, the carbon chain length of alcohol also affects the solubility of the corresponding COSSMs to some extent. For example, (PEG $400+\mathrm{EDA})$-COSSM can be partially dissolved in dichloromethane and ethyl acetate.

Table 2. Solubility of various COSSMs

\begin{tabular}{|c|c|c|c|c|c|c|c|c|}
\hline COSSMs & Water & Hexane & Toluene & Diethyl ether & $\mathrm{CH}_{2} \mathrm{Cl}_{2}$ & Ethyl acetate & Ethanol & DMSO \\
\hline$(\mathrm{EG}+\mathrm{EDA})-\mathrm{COSSM}$ & M & I & I & I & I & I & I & M \\
\hline$(\mathrm{DEG}+\mathrm{EDA})-\mathrm{COSSM}$ & M & I & I & I & I & I & I & M \\
\hline (TEG + EDA)-COSSM & M & I & I & I & I & I & I & M \\
\hline$(\mathrm{TeEG}+\mathrm{EDA})-\mathrm{COSSM}$ & M & I & I & I & I & I & I & M \\
\hline$(\mathrm{PEG} 300+\mathrm{EDA})-\mathrm{COSSM}$ & M & I & I & I & I & I & I & M \\
\hline (PEG $400+$ EDA)-COSSM & M & I & I & I & $\mathrm{P}$ & $\mathrm{P}$ & I & M \\
\hline$(\mathrm{DPG}+\mathrm{EDA})-\mathrm{COSSM}$ & M & I & I & I & I & I & I & M \\
\hline$(\mathrm{PPD}+\mathrm{EDA})-\mathrm{COSSM}$ & M & I & I & I & I & I & I & M \\
\hline$(\mathrm{BDO}+\mathrm{EDA})-\mathrm{COSSM}$ & M & I & I & I & I & I & I & M \\
\hline$(\mathrm{EG}+\mathrm{PDA})-\mathrm{COSSM}$ & M & I & I & I & I & I & I & M \\
\hline$(\mathrm{EG}+\mathrm{HDA})-\mathrm{COSSM}$ & M & I & I & I & I & I & I & M \\
\hline
\end{tabular}

$\mathrm{I}=$ immiscible, $\mathrm{M}=$ miscible, $\mathrm{P}=$ partially miscible

\subsubsection{Yields}

To compare the COS absorption efficiencies of different EGs + EDAs binary systems, the COS increments of different binary systems under the same conditions are measured. As shown in Table 1, the COS increments are in the range of 2.8119-11.8875 g, and the highest COS absorption efficiency is obtained with the EG + EDA binary system. The molecular masses of EG and EDA are the closest, and thus their intermolecular interaction is the strongest, which is most conducive to the fixation of COS. 


\subsection{Utilization of COSSMS}

\subsubsection{Characterization of CdS NPS \\ 3.2.1.1 FTIR}

Figure 5a shows the FTIR spectra of CdS NPs of three conditions.

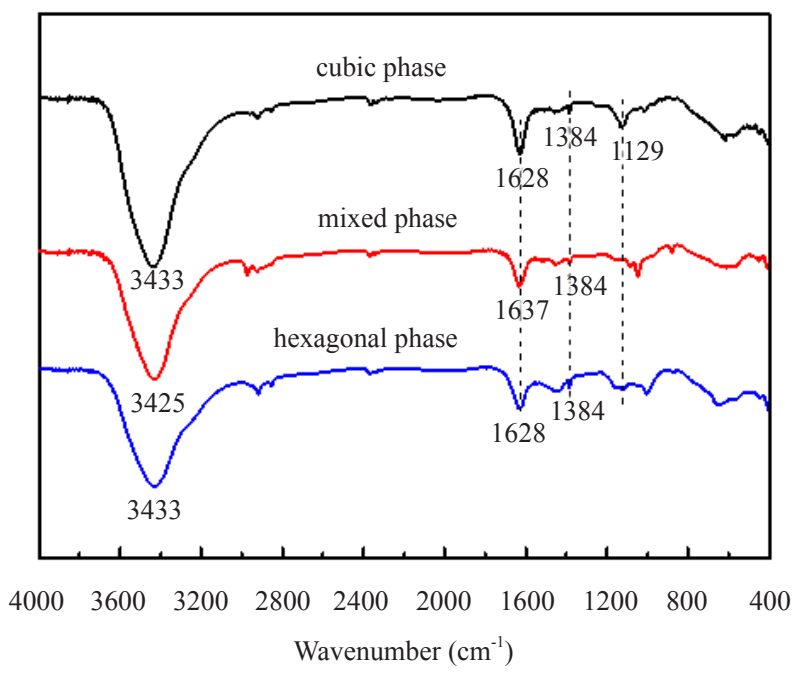

(a)

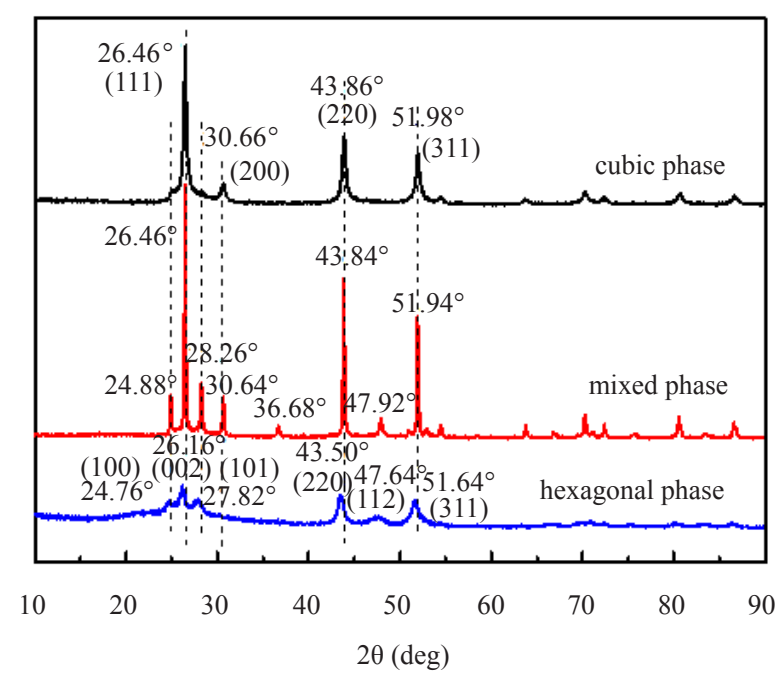

(b)

Figure 5. FTIR spectra (a) and XRD patterns (b) of CdS of three conditions

The CdS NPs prepared with the COSSMs show peaks at $3330 \mathrm{~cm}^{-1}$ and $1628 \mathrm{~cm}^{-1}$, that are attributed to the stretching vibration and bending vibration of $\mathrm{O}-\mathrm{H}$ in the adsorbed water. ${ }^{43}$ The characteristic peaks at $1384 \mathrm{~cm}^{-1}$ and $1129 \mathrm{~cm}^{-1}$ are assigned to the stretching vibration of Cd-S. ${ }^{44}$

\subsubsection{XPS}

The full scan XPS spectra of CdS NPs prepared under different conditions and the high-resolution Cd(3d) and S(2p) XPS reveal four elements: C, O, Cd, and S (Figure S3). C and O are from the interference peaks of the instrument. The binding energy of $\mathrm{Cd} 3 \mathrm{~d} 5 / 2$ peak is $404.63 \mathrm{eV}$ and that of $\mathrm{Cd} 3 \mathrm{~d} 3 / 2$ peak is $411.33 \mathrm{eV}$. The difference between the binding energies is $6.70 \mathrm{eV}$, the typical characteristics of $\mathrm{Cd}^{2+}$ in CdS NPs. ${ }^{45}$ The S 2p3/2 and S 2p1/2 peaks are found at $160.88 \mathrm{eV}$ and $161.98 \mathrm{eV}$ with a difference of $1.10 \mathrm{eV}$, suggesting that $\mathrm{S}$ in the CdS NPs is in the form of $\mathrm{S}^{2-46}$ These results suggest the CdS NPs have been successfully prepared with COSSMs.

\subsubsection{XRD}

Figure $5 \mathrm{~b}$ shows the XRD patterns of the CdS NPs prepared under different conditions. The strong diffraction peaks of the CdS NPs prepared with $0.1 \mathrm{~g}$ EG-based COSSM at $26.46^{\circ}, 30.66^{\circ}, 43.86^{\circ}$ and $51.98^{\circ}$, respectively, correspond to the (111), (200), (220), and (311) planes of the cubic CdS crystals (JCPDS, 89-0440). ${ }^{47}$ The CdS NPs prepared at $60^{\circ} \mathrm{C}$ exhibits diffraction peaks at $24.76^{\circ}, 26.16^{\circ}, 27.82^{\circ}, 43.50^{\circ}, 47.64^{\circ}$, and $51.64^{\circ}$, that can be assigned to the (100), (002), (101), (220), (112), and (311) planes of hexagonal CdS crystals (JCPDS, 77-2306). ${ }^{48}$ The CdS NPs sample displaying all these diffraction peaks consists of both cubic (JCPDS 89-0440) and hexagonal (JCPDS 89-2944) phases. It also shows that the cubic phase and the hexagonal phase of CdS NPs have a huge difference at the 200 and 112 crystal planes.

The ratio of CdS crystal phase was calculated by Eq. (1): 


$$
F w=\frac{R}{k_{1}-\left(k_{1} k_{2}-1\right) R}
$$

where $F w$ represents the content of the hexagonal phase in the CdS crystal phase, $R$ represents the intensity ratio of the overlapping peaks of the hexagonal phase (100) crystal plane to the cubic phase (111) crystal plane, and the hexagonal phase (002) crystal plane, $k_{1}$ is 0.341 , indicating the strength ratio of the hexagonal phase (100) crystal plane to the cubic (111) crystal plane, $k_{2}$ is 0.825 , representing the intensity ratio of the hexagonal phase (002) crystal plane and the hexagonal phase (100) crystal plane. According to Eq. (1), the relative contents of the cubic phase and hexagonal phase are determined with Eq. 1 to be $67 \%$ and $33 \%$, respectively.

\subsubsection{SEM}

Figure 6a shows SEM images of CdS NPs of three conditions.

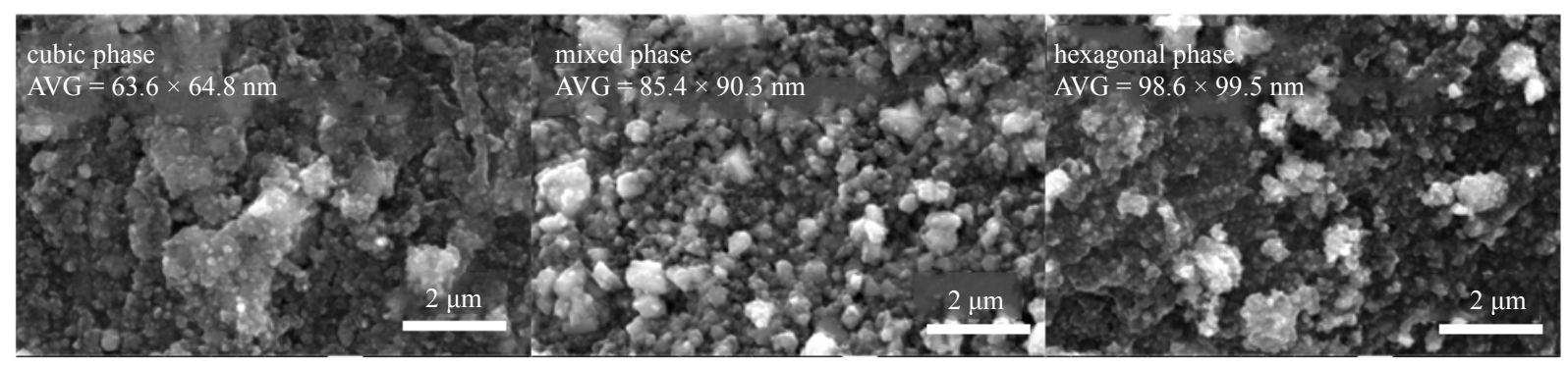

(a)
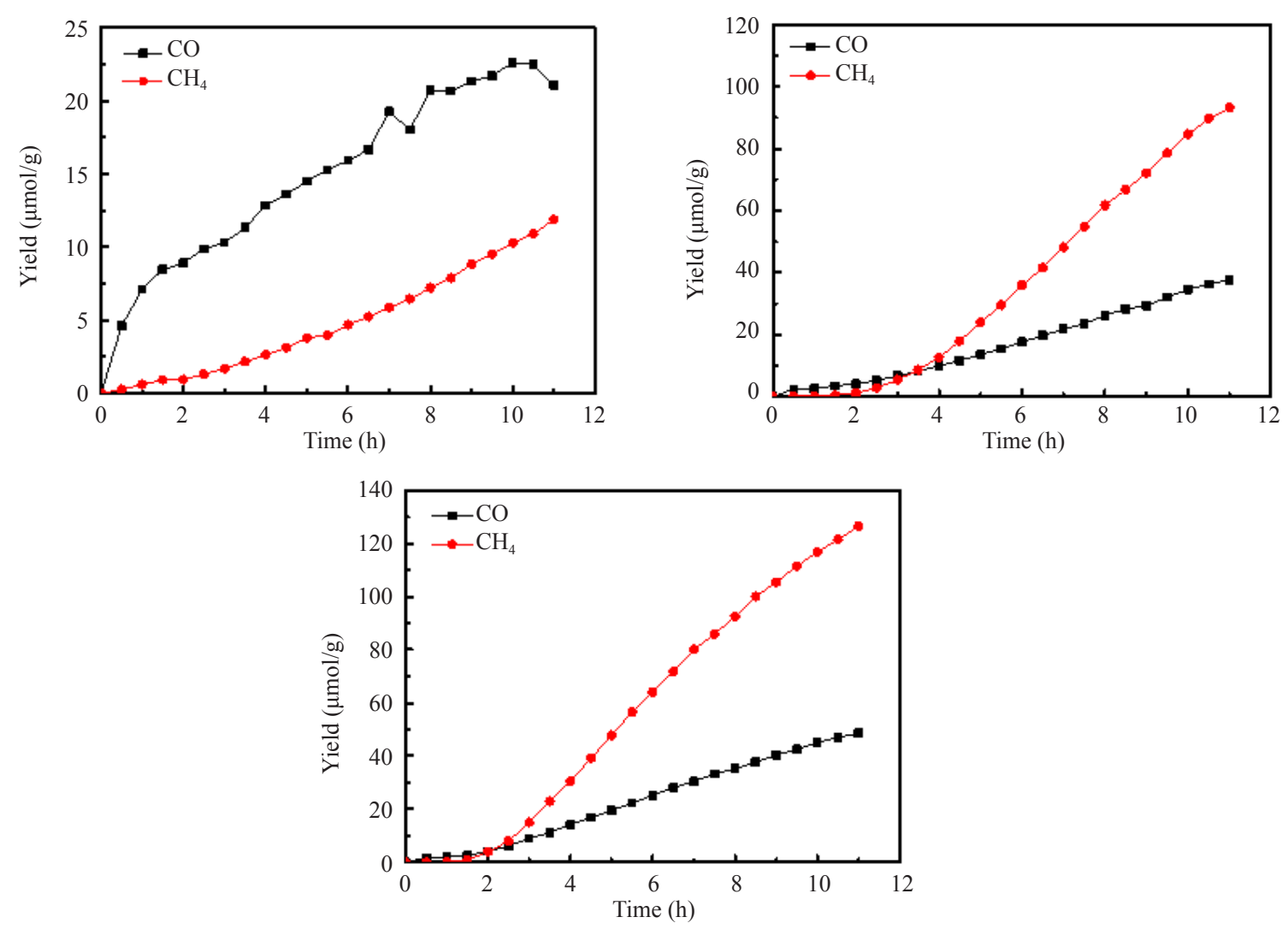

(b)

Figure 6. SEM images (a) and photocatalytic $\mathrm{CO}_{2}$ reduction (b) of three CdS catalysts 
The morphologies of the CdS NPs prepared under different conditions were studied by SEM. As shown in Figure 6a, all the NPs are amorphous and their surfaces are composed of cubic, hexagonal, or the mixed of cubic and hexagonal particles. Their average particle sizes are measured to be $63.6 \mathrm{~nm} \times 64.8 \mathrm{~nm}, 98.6 \mathrm{~nm} \times 99.5 \mathrm{~nm}$, and $85.4 \mathrm{~nm} \times 90.3$ nm, respectively.

Based on these characterization results, the formation mechanism of CdS NPs from COSSMs is proposed as follows. ${ }^{49}$

$$
\begin{aligned}
& \mathrm{COSSM}_{\mathrm{EG}} \rightarrow \mathrm{COS}+\mathrm{EDA}+\mathrm{EG}+\mathrm{S}^{2-} \\
& \left.\mathrm{EG}(\text { and/or EDA })+\mathrm{Cd}^{2+} \rightarrow{\mathrm{EG}-\mathrm{Cd}^{2+}(\text { and/or EDA-Cd }}^{2+}\right) \\
& \left.\mathrm{EG}(\text { and/or EDA })+\mathrm{S}^{2-} \rightarrow{\mathrm{EG}-\mathrm{S}^{2-}(\text { and/or EDA-S }}^{2-}\right) \\
& \text { EG-Cd }{ }^{2+}\left(\text { and/or EDA-Cd }{ }^{2+}\right)+\text { EG-S }^{2-}\left(\text { and/or EDA-S }{ }^{2-}\right) \rightarrow \mathrm{CdS}+\mathrm{EG}(\text { and/or EDA }) \\
& \mathrm{COS}+\mathrm{H}_{2} \mathrm{O}=\mathrm{H}_{2} \mathrm{~S}+\mathrm{CO}_{2} \\
& \mathrm{H}_{2} \mathrm{~S}=\mathrm{HS}^{-}+\mathrm{H}^{+} \\
& \mathrm{HS}^{-}=\mathrm{H}^{+}+\mathrm{S}^{2-} \\
& \mathrm{S}^{2-}+\mathrm{Cd}^{2+}=\mathrm{CdS} \downarrow
\end{aligned}
$$

The COSSM provides $\mathrm{S}^{2-}$ for the formation of CdS NPs. The EDAs and EGs released from COSSMs function as the surfactant to control the nucleation, growth, crystal form, and orientation of CdS crystals. As shown above, the $\mathrm{COSSM}_{\mathrm{EG}}$ releases COS and $\mathrm{S}^{2-}$ in solution. COS then undergoes hydrolysis reaction to form $\mathrm{H}_{2} \mathrm{~S}$. $\mathrm{H}_{2} \mathrm{~S}$ is deprotonated into $\mathrm{HS}^{-}$under certain conditions. $\mathrm{HS}^{-}$can decompose to $\mathrm{S}^{2-} . \mathrm{S}^{2-}$ from both sources reacts with $\mathrm{Cd}^{2+}$ to form the final product CdS NPs.

\subsubsection{Application of CdS NPs}

\subsubsection{Photocatalytic $\mathrm{CO}_{2}$ reduction}

The application of the prepared CdS NPs as the photocatalyst for $\mathrm{CO}_{2}$ reduction was first explored. The cubic, hexagonal and mixed phase CdS NPs $(0.05 \mathrm{~g})$ were respectively added $100 \mathrm{~mL}$ airtight quartz reactors containing 10 $\mathrm{mL}$ of Triethanolamine (TEOA) sacrificial agent, $20 \mathrm{~mL}$ of deionized water, and a magnetic stir bar. The reactor was evacuated to check the airtightness of the system. $\mathrm{CO}_{2}$ gas (99.999\% purity) was introduced into the reactor to reach the pressure of $0.079 \mathrm{MPa}$ and allowed to react under the irradiation at the light intensity of $20 \mathrm{~A}$ and stirring. The gases in the reactor were sampled every $30 \mathrm{~min}$ and analyzed by gas chromatography.

As shown in Figure 6b, the reduction over pure cubic CdS NPs selectively produces CO, and that over pure hexagonal $\mathrm{CdS}$ catalyst covert $\mathrm{CO}_{2}$ to $\mathrm{CH}_{4}$. The reaction is finished in $660 \mathrm{~min}$. The yields of $\mathrm{CO}$ over the $\mathrm{CdS} \mathrm{NPs}$ of cubic, mixed and hexagonal phases are $22.61 \mu \mathrm{mol} / \mathrm{g}, 37.74 \mu \mathrm{mol} / \mathrm{g}$, and $48.62 \mu \mathrm{mol} / \mathrm{g}$, and those of $\mathrm{CH}_{4}$ are 11.89 $\mu \mathrm{mol} / \mathrm{g}, 93.16 \mu \mathrm{mol} / \mathrm{g}$, and $126.53 \mu \mathrm{mol} / \mathrm{g}$. The yields over the catalyst of the mixed phase are higher than those reported in the literature. ${ }^{50}$

\subsubsection{Promoting plant growth}

The vegetative growth of a plant can be evaluated with its height, average stem diameter, leaf size, and root development. The application of COSSMs significantly improves the vegetative growths of the plants as demonstrated with the improved plant heights (Table S3-S6, Figure S4 and 7), leaf sizes (Table S7 and S8 and Figure S5), average stem diameters (Table S9), and root development (Table S10-S12 and Figure 7). The irrigation with COSSMs also promotes the reproductive growths of the plants with more flowers and fruits (Table 3, Figure S6 and S7). These results suggest that COSSMs can function as a fertilizer to promote both vegetative growth and reproductive growth of the plant. 

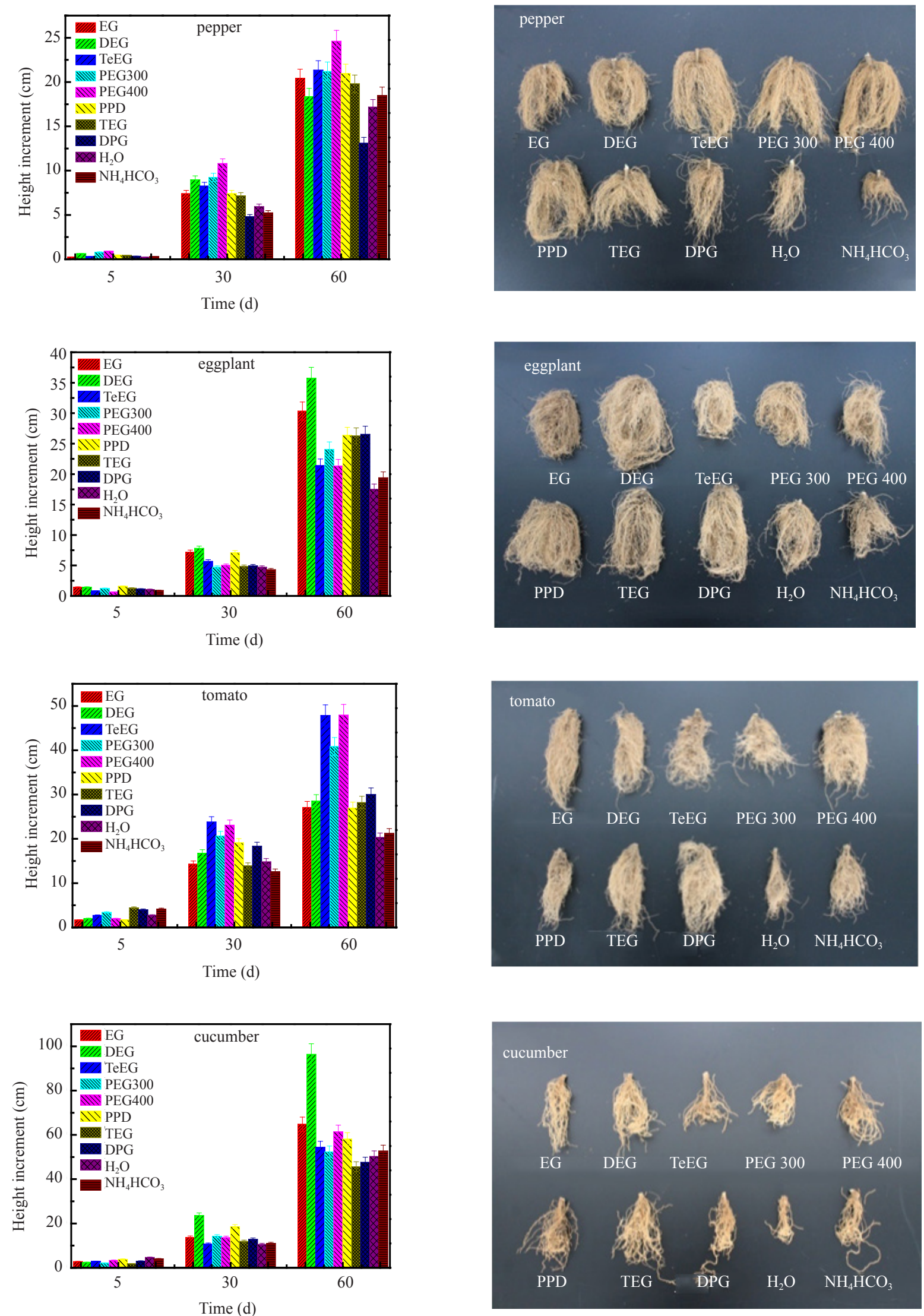

Figure 7. Average growth of plants at $5 \mathrm{~d}, 30 \mathrm{~d}$ and $60 \mathrm{~d}$ and the growth of plant roots 
Table 3. Statistics of flowering and fruit number of pepper, eggplant, tomato and cucumber

\begin{tabular}{|c|c|c|c|c|c|c|c|c|}
\hline \multirow{3}{*}{ COSSM } & \multicolumn{8}{|c|}{ Flowering period and number of fruits } \\
\hline & \multicolumn{2}{|c|}{ Pepper } & \multicolumn{2}{|c|}{ Eggplant } & \multicolumn{2}{|c|}{ Tomato } & \multicolumn{2}{|c|}{ Cucumber } \\
\hline & $30 \mathrm{~d}$ & $60 \mathrm{~d}$ & $26 \mathrm{~d}$ & $60 \mathrm{~d}$ & $5 \mathrm{~d}$ & $60 \mathrm{~d}$ & $18 \mathrm{~d}$ & $60 \mathrm{~d}$ \\
\hline Water & $\mathrm{N}$ & 8 & $\mathrm{~N}$ & 1 & $\mathrm{~N}$ & 18 & $\mathrm{Y}(1)$ & 1 \\
\hline $\mathrm{NH}_{4} \mathrm{HCO}_{3}$ & $\mathrm{Y}(1)$ & 12 & $\mathrm{~N}$ & 1 & $\mathrm{Y}(1)$ & 19 & $\mathrm{Y}(1)$ & 1 \\
\hline EG-COSSM & $\mathrm{Y}(2)$ & 16 & $\mathrm{Y}(2)$ & 3 & $\mathrm{Y}(4)$ & 27 & $\mathrm{Y}(2)$ & 2 \\
\hline DEG-COSSM & $\mathrm{Y}(3)$ & 12 & $\mathrm{Y}(3)$ & 2 & $\mathrm{Y}(5)$ & 32 & $\mathrm{~N}$ & 2 \\
\hline TeEG-COSSM & $\mathrm{N}$ & 20 & $\mathrm{Y}(3)$ & 1 & $\mathrm{Y}(4)$ & 28 & $\mathrm{Y}(1)$ & 3 \\
\hline PEG 300-COSSM & $\mathrm{Y}(1)$ & 15 & $Y(3)$ & 1 & $\mathrm{Y}(2)$ & 27 & $\mathrm{Y}(2)$ & 2 \\
\hline PEG 400-COSSM & $\mathrm{N}$ & 13 & $\mathrm{Y}(2)$ & 2 & $\mathrm{Y}(2)$ & 30 & $\mathrm{Y}(3)$ & 3 \\
\hline PPD-COSSM & $\mathrm{N}$ & 21 & $\mathrm{Y}(4)$ & 1 & $\mathrm{Y}(4)$ & 31 & $\mathrm{~N}$ & 2 \\
\hline TEG-COSSM & $\mathrm{N}$ & 16 & $Y(3)$ & 1 & $\mathrm{Y}(3)$ & 29 & $\mathrm{Y}(4)$ & 2 \\
\hline DPG-COSSM & $\mathrm{Y}(4)$ & 9 & $\mathrm{Y}(1)$ & 2 & $\mathrm{Y}(4)$ & 29 & $\mathrm{Y}(1)$ & 2 \\
\hline
\end{tabular}

*Y and $\mathrm{N}$ in the table stand for blooming or not when measured

To understand the plant growth promoting mechanism of COSSMs, the soils in the flowerpots of both experimental and control groups were sampled after the experiment and measured for total nitrogen content, total sulfur content, and $\mathrm{pH}$ value (Table S13). It is found that the irrigation of COSSMs solution has no significant effects on the $\mathrm{pH}$ of soil. Studies have shown that $\mathrm{N}$ and $\mathrm{S}$ elements can improve the growth and development of plant roots and leaves, as well as yield. ${ }^{51}$ COSSMs may promote the absorption of $\mathrm{N}$ and $\mathrm{S}$ of plants, and thus further promote the growth and development of the plants. No significant difference found between pHs of the soils indicates that COSSMs promote plant growth and development by providing a combination of many elements. ${ }^{52}$

\section{Conclusion}

A novel COS capture, storage, and utilization approach has been developed under ambient conditions. COS is absorbed with Ethylene Glycol-based polyols (EGs) + Ethylenediamine-based polyamines (EDAs) binary systems to form COSSMs with the structure of $\left[{ }^{+} \mathrm{H}_{3} \mathrm{NR}_{1} \mathrm{NH}_{3}{ }^{+-} \mathrm{OC}(=\mathrm{S}) \mathrm{OR}_{2}\left(\mathrm{R}_{3}\right) \mathrm{O}(\mathrm{S}=) \mathrm{CO}^{-}\right]_{\mathrm{n}}$, which was confirmed by various spectral technologies. The sustainable utilization of COS is demonstrated with the successful applications of COSSMs to the synthesis of CdS NPs for the photocatalytic conversion of $\mathrm{CO}_{2}$ to $\mathrm{CO}$ and $\mathrm{CH}_{4}$ with the excellent photocatalytic performance, and to promote plant growth, including eggplant, pepper, tomato, and cucumber, as a nitro-sulfur compound fertilizer with its height, average stem diameter, leaf size, and root development.

\section{Acknowledgments}

This work was supported by the Inner Mongolia Science and Technology Key Projects, the Program for Grassland Excellent Talents of Inner Mongolia Autonomous Region, and Beijing Boyuan Hengsheng High-Tech. Co., Ltd., Beijing, China (HA2157). 


\section{Conflicts of interests}

The authors declare no competing financial interest.

\section{References}

[1] Brühl, C.; Lelieveld, J.; Crutzen, P. J.; Tost, H. Chem. Phys. 2012, 12, 1239-1253.

[2] Khalil, M. A. K.; Rasmussen, R. A. Atmos. Environ. 1984, 18, 1805-1813.

[3] Du, Q. Q.; Mu, Y. J.; Zhang, C. L.; Liu, J. F.; Zhang, Y. Y.; Liu, C. T. J. Environ. Sci. 2017, 51, $146-156$.

[4] Zhang, Y. Q.; Xiao, Z. B.; Ma, J. X. Appl. Catal. B. 2004, 48, 57-63.

[5] Yan, Y. L.; Li, R. M.; Peng, L.; Yang, C.; Liu, C. L. Cao, J. Y.; Yang, F.; Li, Y. H.; Wu, J. Environ. Pollut. 2019, 247, 745-751.

[6] Sakanishi, K.; Wu, Z.; Matsumura, A.; Saito, I.; Hanaoka, T.; Minowa, T.; Tada, M.; Iwasaki, T. Catal. Today. 2005, 104, 94-100.

[7] Wang, H. Y.; Yi, H. H.; Ning, P. X.; Tang, L.; Yu, L. L.; He, D.; Zhao, S. Z. Chem. Eng. J. 2011, 166, 99-104.

[8] Ogawa, T.; Noguchi, K.; Saito, M.; Nagahata, Y.; Kato, H.; Ohtaki, A.; Nakayama, H.; Dohmae, N.; Matsushita, Y.; Odaka, M.; Yohda, M.; Nyunoya, H. Katayama, Y. J. Am. Chem. Soc. 2013, 135, 3818-3825.

[9] Ferm, R. J. Chem. Rev. 1957, 57, 621-640.

[10] Svoronos, P. D. N.; Bruno, T. J. Ind. Eng. Chem. Res. 2002, 41, 5321-5336.

[11] He, E. Y.; Huang, G.; Fan, H. L.; Yang, C.; Wang, H.; Tian, Z.; Wang, L. J.; Zhao, Y. R. Fuel. 2019, 246, $277-284$.

[12] Li, C. P.; Zhang, J. B.; Zhang, T. X.; Wei, X. H.; Zhang, E. Q.; Yang, N.; Zhao, N. N.; Su, M. Zhou, H. J. Chem. Eng. Data. 2010, 55, 4104-4107.

[13] Chen, X.; Shen, S.; Guo, L.; Mao, S. S. Chem. Rev. 2010, 110, 6503-6570.

[14] White, J. L.; Baruch, M. F.; Pander, J. E.; Hu, Y.; Fortmeyer, I. C.; Park, J. E.; Zhang, T.; Liao, K.; Gu, J.; Yan, Y.; Shaw, T. W.; Abelev, E.; Bocarsly, A. B. Chem. Rev. 2015, 115, 12888-12935.

[15] Li, Z. P.; Cheng, H. B.; Li, Y. F.; Yu, Y. ACS Sustain. Chem. Eng. 2019, 7, 4325-4334.

[16] Song, G. X.; Xin, F.; Chen, J. S.; Yin, X. H. Appl. Catal. A-Gen. 2014, 473, 90-95.

[17] Valle, S. F.; Giroto, A. S.; Klaic, R.; Guimaraes, G. G. F.; Ribeiro, C. Polym. Degrad. Stab. 2019, 162, $102-105$.

[18] Chien, S. H.; Gearhart, M. M.; Villagarcía, S. Soil Sci. 2011, 176, 327-335.

[19] Sun, L. J.; Xue, Y.; Peng, C.; Xu, C.; Shi, J. Y. Environ. Pollut. 2018, 243, 1119-1125.

[20] Luo, L.; Xu, C.; Ma, Y. B.; Zheng, L.; Liu, L. J.; Lv, J. T.; Zhang, S. Z. Soil Sci. Soc. Am. J. $2014,78,1615$.

[21] Yang, J. J.; Zhu, S. H.; Zheng, C. Q.; Sun, L. J.; Liu, J.; Shi, J. Y. J. Hazard Mater. 2015, 286, 432-439.

[22] Zhao, T. X.; Guo, B.; Han, L. M.; Zhu, N.; Gao, F.; Li, Q.; L. Li, H.; Zhang, J. B. ChemPhysChem. 2015, 16, 21062109.

[23] Meng, X. L.; Li, X. F.; Shi, H. H.; Wu, J. M.; Wu, Z. J. J. Mol. Liq. 2016, 219, 677-689.

[24] Yue, X. Q.; Li, Q.; Li, B.; Zhao, L.; Wu, Y.; Yang, T. Y.; Liu, K.; Zhang, J. B.; Zhu, N. J. Clean. Prod. 2019, 237, 117710.

[25] Tao, Y.; Taisuke, Y.; Richard, G. W. Chem. Mater. 2010, 22, 5492-5499.

[26] Chang, B.; Wu, Y. Chin. J. Syn. Chem. 2018, 26, 425-428.

[27] Yoshida, Baba, Y. O.; Saito, G. J. Phys. Chem. B., 2007, 111, 4742-4749.

[28] Fraser, K. J.; Izgorodina, E. I.; Forsyth, M. J.; Scott, L.; MacFarlane, D. R. Chem. Commun. 2007, $37,3817-3819$.

[29] Danon, A.; Stair, P. C.; Weitz, E. J. Phys. Chem. C. 2011, 115, 11540-11549.

[30] Xie, J. X.; Chang, J. B.; Wang, X. M. Applications of Infrared Spectroscopy in Organic Chemistry and Medicinal Chemistry (in Chinese); Science Press: Beijing. 2001.

[31] Chang, Q.; Hao, X. K.; Duan, L. L. J. Hazard. Mater. 2008, 159, 548-553.

[32] Xie, R. S.; Li, Y. L.; Huang, H. Y.; Pan, X. Q.; Guo, B. G.; Liu, H. F.; Hu, H. L. Zhang, X. Q.; Ma, Y. J. J. Alloy. Compd. 2019, 782, 28-37.

[33] Mir, F. A.; Chattarjee, I.; Dar, A. A.; Asokan, K.; Bhat, G. M. Optik. 2015, 126, 1240-1244.

[34] Gosavi, R. K.; Agarwala, U.; Rao, C. N. R. J. Am. Chem. Soc. 1967, 89, 235-239.

[35] Yang, Y. J.; Xu, L. J.; Li, W. Y.; Fan, W. J.; Song, S.; Yang, J. Appl. Catal. B-Environ. 2019, $259,118057$.

[36] Yu, D. D.; Bai, J.; Liang, H. O.; Li, C. P. J. Alloys Compd. 2016, 683, 329-338.

[37] Hao, R. L.; Zhang, Y. Y.; Wang, Z. Y.; Li, Y. P.; Yuan, B.; Mao, X. Z.; Zhao, Y. Chem. Eng. J. $2017,307,562-571$.

[38] Sha, F.; Zhu, N.; Bai, Y. J.; Li, Q.; Guo, B.; Zhao, T. X.; Zhang, F.; Zhang, J. B. ACS Sustainable Chem. Eng. 2016, 
4, 3032-3044.

[39] Ge, Y. Y.; Xiao, D.; Li, Z. L.; Cui, X. M. J. Mater. Chem. A. 2014, 2, 2136-2145.

[40] Zhang, R. M.; Yue, X. Q.; Li, B.; Yang, J. R.; Wu, Z. J.; Zhang, J. B. J. Mol. Liq. 2020, 299, 112213.

[41] Yingquan, H.; Shimoyama, Y. Fluid. Phase. Equilib. 2019, 494, 115-124.

[42] Goossens, K.; Nockemann, P.; Driesen, K.; Goderis, B.; Walrand, C. G.; Hecke, K. V.; Meervelt, L. V.; Pouzet, E. Chem. Mater. 2008, 20, 157-168.

[43] Kumar, A.; Reddy, K. L.; Kumar, S.; Kumar, A.; Sharma, V.; Krishnan, V. ACS Appl. Mater. Interf. 2018, 10, $15565-15581$

[44] Wang, Y. Y.; Zhang, X.; Liu, Y. J.; Zhao, Y. B.; Xie, C.; Song, Y. X.; Yang, P. Int. J. Hydrogen Energy. 2019, 44, 30151-30159.

[45] Hao, D. D.; Shen, Q. H.; Liu, J.; Wei, L. F.; Bibi, R.; Fu, B.; Lia, N. X.; Zhou, J. C. Int. J. Biol. Macromol. 2019, $141,1111-1117$

[46] Liu, Y.; Deng, L.; Sheng, J. P.; Tang, F. Y.; Zeng, K.; Wang, L. Q.; Liang, K. X.; Hu, H.; Liu, Y. N. Appl. Surf. Sci. 2019, 498, 143899

[47] Wu, X. Q.; Zhao, J.; Wang, L. P.; Han, M. M.; Zhang, M. L.; Wang, H. B.; Huang, H.; Liu, Y. Kang, Z. H. Appl. Catal. B-Environ. 2017, 206, 501-509.

[48] Pan, B.; Qin, J. N.; Wang, X. X.; Su, W. Y. Appl. Surf. Sci. 2020, 504, 144379.

[49] Zhao, T. X.; Guo, B.; Zhang, F.; Sha, F.; Li, Q.; Zhang, J. B. ACS Appl. Mater. Interfaces. 2015, 7, $15918-15927$.

[50] Xie, S. L.; Liu, J.; Dong, L. Z.; Li, S. L.; Lan, Y. Q.; Su, Z. M. Chem. Sci. 2019, 10, 185-190.

[51] Zhang, D.; Li, W.; Xin, C.; Tang, W.; Eneji, A. E.; Dong, H. Field Crop. Res. 2012, 138, 63-70.

[52] André, A. D. C. L.; Chaer, G. M.; Fábio, B. D. R. J.; Goedert, W. J.; Iêda, D. C. M. Soil Sci. Soc. Am. J. 2013, 77, 461-472. 